щих и его оценки // Системная психология и социология. 2011. № 4. С. 37-49.

13. Асеева Ю.А. Влияние морально-психологического состояния на профессиональные установки // Архивариус. 2015. № 4. С. 105-110.

14. Семенкова С.Н. Взаимодополняемость понятий морально-психологическое состояние и педагогический такт // Проблемы и перспективы развития образования в России. 2012. № 14. С. 46-49.

15. Карпов В.Б., Касавцев М.Ю. Диагностика личности курсанта как инструмент повышения качества подготовки военных специалистов [Электронный ресурс] // Письма в Эмиссия.Оффлайн: электронный научный журнал. 2015. № 7 (июль). АRT 2390. http://emissia.org/offline/2015/2390.htm.

16. Николаев А.А., Яковлев Д.С. Рукопашный бой в военно-профессиональной деятельности военнослужащих // Теоретические и практические аспекты развития научной мысли в современном мире: сб. статей Международной научно-практической конференции. 2016. С. 158-161.

17. Касавцев М.Ю. Методика воспитания военных специалистов на личном примере офицера // Альманах современной науки и образования. 2016. № 2 (104). С. 63-65.

18. Губин В.А., Егоров Д.А. Психолого-педагогическая модель воспитания военнослужащих-контрактников на личном примере офицера // Ученые записки. 2014. № 7 (113). С. 50-58.

19. Психология и педагогика / под ред. Н.В. Ершова. СПб.: ВКА имени А.Ф. Можайского. 2011. 515 с.

20. Дербин П.А. Социально-психологические технологии формирования стрессоустойчивости у военнослужащих // Успехи современного естествознания. 2012. № 6. C. 213-214.

\title{
THE MONITORING TECHNIQUE OF THE SOLDIER STATE IN THE PROCESS OF PSYCHO-PEDAGOGICAL TRAINING IN THE ORGANIZATION AND GUARD DUTY
}

(C) 2016

M.Y. Kasavtsev, candidate of technical sciences, senior lecturer of Daily Activities Organization and Combat Training Department Military Space Academy named A.F. Mozhaysky, Saint Petersburg (Russia)

Abstract. The following paper deals with the problem of military personnel training for guard duty and their moral and psychological maintenance during their duty. The division commander, being responsible for the guard personnel training should have a set of techniques, ways and methods of military personnel training for duty, while the guard chief, in addition, must be able to timely detect, identify and neutralize negative effects of stress on the personality of military personnel members of the guard. Surveys with the guard personnel revealed the contradiction between the requirements to military personnel and the actual state of psychological microclimate in the guard. It is obvious that the leveling of the stress influence on the soldier's personality will have a positive impact on the psychological microclimate of the guard personnel, but it should be done without any damage to the combat mission quality. The author has found a solution and created a method of the soldier state monitoring in the organization and guard duty. The application of this method has improved the quality of combat mission execution by guard personnel.

Keywords: guard duty; combat mission quality; soldiers' stress; personality diagnosis; psychological climate in the guard; psychological and educational impact on the soldier's personality; guard duty preparation and organization in the unit.

УДК 37.035 .6

\section{ПАТРИОТИЗМ КАК ВЕДУЩАЯ ИДЕЯ ВОСПИТАНИЯ РОССИЙСКОЙ МОЛОДЕЖИ В СОВРЕМЕННОМ СОЦИУМЕ}

(C) 2016

\section{Е.Л. Крылова, директор}

филиал «Государственная телевизионная и радиовещуательная компания "Самара"» Всероссийской государственной телевизионной и радиовещательной компании, Самара (Россия)

Аннотация. В статье рассматривается проблема значимости патриотизма. Обосновывается утверждение, что патриотизм является ведущей идеей воспитания российской молодежи и подчеркивается необходимость комплексного подхода к процессу формирования патриотического сознания молодых людей. Аргументируется, что механизм патриотического воспитания молодежи является совокупностью методов и средств развития, функционирования и сохранения морально-этического мировоззрения патриотической направленности. Обосновывается важность воспитания молодого поколения на принципах уважения к историческому прошлому страны, любви к Родине и национальной культуре, так как именно молодежь обеспечивает продуктивное развитие сильного государства и здорового общества. Устанавливается взаимосвязь между успешным будущим страны и сформированным патриотическим сознанием молодежи, ядро которого составляют общечеловеческие ценности. Доказывается, что истинный патриотизм можно только пробудить, а не навязать, так как особенно остро на информационное давление реагируют представители молодого поколения. Выдвигается в качестве актуальной воспитательной задачи СМИ создание качественного информационного продукта, адаптированного под особенности молодежной аудитории. В данном контексте работа СМИ по формированию патрио- 
тического сознания молодежи рассматривается как целенаправленная деятельность работников СМИ, основанная на совокупности специальных знаний, умений, навыков, ценностей, по формированию у молодых людей чувства любви и верности своему Отечеству, готовности защитить свой народ, Родину и ее интересы.

Ключевые слова: патриотизм; воспитание; молодое поколение; идея; общественная жизнь; патриотическое сознание; СМИ; историческая память; пропаганда исторического прошлого; государственная программа; информационный продукт; культивирование патриотизма; общественная идеология.

В общественной и политической жизни современной России проблема патриотизма является актуальной и одной из самых изучаемых. Последствия резкой смены общественных формаций и системы ценностей стали определяющим фактором изменения отношения общества к патриотизму. Патриотизм всегда играл важнейшую роль в самосознании России, его глубинные основы становились идеологической площадкой и базисом во всех сферах общественной жизни - политике, культуре, литературе, истории, педагогике, воспитании многих поколений россиян. В современных условиях санкций и политической ангажированности этот факт нельзя недооценивать [1, с. 288].

В последнее время проблема патриотического воспитания и формирования патриотического сознания молодежи приобрела общенациональный характер. Это обусловлено тем, что в период реформ были утрачены идеологические основы. Исторические процессы и роль личности в них трактовались разнонаправленно, у молодого поколения российских граждан не осталось достойных образцов для подражания, литературных героев, что в конечном итоге превратилось в общегосударственную проблему.

Теоретические представления о понятии «патриотизм» и о формировании патриотического сознания достаточно многоплановы. Данные представления берут свое начало в лингвистическом толковании слова «патриот». В Толковом словаре живого великорусского языка В.И. Даля патриот - «любитель отечества, ревнитель о благе его» [2, с. 398]. Согласно Толковому словарю русского языка С.И. Ожегова патриот - это «человек, преданный своему Отечеству, своему народу» [3, с. 697].

В трактовке слова «патриота» в словаре В.И. Даля, на наш взгляд, наблюдается существенное отличие от его трактовки в словаре С.И. Ожегова. У В.И. Даля патриот - ревнитель о благе Отечества, иными словами человек, стремящийся что-то сделать для своего Отечества. Здесь на первый план выдвигается активность патриота.

Практически во всех языках присутствует производная от «патриот» - слово «патриотизм», наделенное «особым смыслом любви», сохраняющее значение жертвования собственной жизнью во благо отечества $[4$, с. 46$]$.

В.Л. Дубровин утверждает: «Патриотизм включен в научный дискурс с античных времен. О полюсном патриотизме говорили Платон, Сократ, Аристотель. Патриотизм как социологический конструкт укоренился в социологии XX века. Это связано с тем, что сам термин «патриотизм» характеризуется трансграничным теоретическим состоянием, ассоциируется с эпохой возникновения национальных государств и имеет политико-идеологический смысл. Между тем патриотизм и сопутствующие ему формы социальной рациональности укрепился в социально-психологической мысли (Г. Лебон) и часто стал восприниматься как инструмент «промывания мозгов» и манипулирования сознанием масс» [5, с. 53].
Ресурс исторической памяти оказывает влияние на схемы восприятия жизни и утверждение референтных образцов социального поведения. Поэтому в условиях социальных и культурных разрывов патриотизм может из эфемерного чувства воспоминания о великих и ушедших эпохах трансформироваться в реальную схему социальной консолидации на основании реализации программ социального и гражданского участия на различных уровнях общественной жизни: страны, региона, отдельного района.

Ж.Т. Тощенко, рассматривая парадоксальность общественного сознания в современной России, подчеркивает, что патриотизм испытывает определенный когнитивный диссонанс, декларируемые позиции часто совмещаются с реальным социальным самоизоляционизмом [6, с. 34].

Гражданское общество в России не может быть ничем иным, как обществом патриотов. К такому выводу приходят российские исследователи Л.М. Дробижева [7] и О.Б. Подвинцев [8]. Соглашаясь с учеными, разовьем их мысль и скажем, что создание системы патриотического воспитания, формирование патриотического сознания, просвещение и пропаганда исторического подвига народа является приоритетом государственной политики и стратегическим направлением развития нашей страны в условиях террористических угроз, экстремизма и ксенофобии, что неоднократно подчеркивалось в выступлениях Президента РФ и его Посланиях Законодательному Собранию.

По инициативе Правительства Российской Федерации была разработана государственная программа «Патриотическое воспитание граждан Российской Федерации на 2016-2020 годы», целью которой является создание условий для повышения гражданской ответственности за судьбу страны, повышения уровня консолидации общества для решения задач обеспечения национальной безопасности и устойчивого развития Российской Федерации, укрепления чувства сопричастности граждан к великой истории и культуре России, обеспечения преемственности поколений россиян, воспитания гражданина, любящего свою Родину и семью, имеющего активную жизненную позицию [9]. Текущая версия Программы разработана на период с 2016 по 2020 годы и предусматривает создание механизмов взаимодействия государства и СМИ в формировании патриотического сознания россиян.

Роль СМИ в повышении уровня патриотизма общества в целом и в формировании патриотического сознания молодежи в особенности сегодня как никогда ранее велика. Президент РФ утверждает: «В наше время нужно именно на примере реальных героев воспитывать молодежь, а не на примере вымышленных западных героев, которые заполонили средства массовой информации последние 20 лет. Память к историческому прошлому нашей Родины - святой долг каждого гражданина» [10]. Тем самым Президент РФ ставит конкретную задачу, которую призваны решать СМИ и особенно телевидение. 
Решение поставленной задачи требует анализа запросов молодежной аудитории и создания качественного информационного продукта, адаптированного под ее особенности. Актуальность создания такого продукта определяется и тем, что, как это установлено исследованием В.А. Лукова [11], патриотизм слабо принят в качестве субкультуры молодежи и не стал поведенческим эталоном. В то время как сегодня важным становится понимание патриотизма как нового направления общественной активности на основе реализации социальных и гражданских инициатив и включение его в инструментарий формирования общероссийской идентичности [12, с. 114-115].

Существует мнение, что настоящий патриотизм можно только пробудить, а не навязать, и это относят к задачам СМИ. Пробуждение патриотизма россиян напрямую связано с формированием патриотического сознания молодежи. Мы полагаем, что в данном контексте работа СМИ по формированию патриотического сознания молодежи - это систематическая и целенаправленная деятельность работников СМИ, основанная на совокупности специальных знаний, умений, навыков, ценностей, по формированию у молодых людей чувства любви и верности своему Отечеству, готовности защитить свой народ, Родину и ее интересы.

В структуре патриотизма М.В. Циулина выделяет два взаимосвязанных уровня:

1) обыденный (обыденно-психологический);

2) рациональный, или теоретический (абстрактнологический) [13, с. 58-61].

Когда речь идет об обыденно-психологическом уровне патриотизма, апеллируют главным образом к чувствам и эмоциям, мнениями, традициям, нравам, символам и т.п.

Обыденно-психологический уровень патриотизма наиболее полно иллюстрирует такие его проявления, как любовь к традициям своего народа, своего края, к родной природе, гордость за успехи и вклад своего народа в мировую историю, чувство сожаления и боли за трагические обстоятельства в истории своей Родины.

Абстрактно-логический уровень патриотизма характеризуется единым содержательным началом: «идея Отечества», концентрирующая в себе объем теоретических знаний и основанных на них убеждений о Родине [14, с. 116-117].

Таким образом, патриотизм проявляется в любви к родному языку; в уважительном отношении к прошлому и настоящему, к национальным и культурным традициям; в гордости за достижения Родины.

Как пишет А.К. Быков, основываясь на анализе работ историков, подлинного расцвета патриотизм в России достиг в Петровскую эпоху. Верность интересам Отечества Петр Великий ставил выше всех иных интересов, выше самого государя. Услуги Отечеству, усердие в государственных делах при Петре Великом объявляются высшей доблестью и закрепляются в «Табели о рангах» как важнейшее условие получения чинов, наград и других привилегий [15, с. 102-106].

В то же время патриотизм, по утверждению В.А. Лукова, может являться источником мощнейших разрушений и уничтожения жизни людей, их взаимоотношений и благополучия, но это при условии, если он искажен идеями национального или коммерческо- го эгоизма, фашизма, революционного или религиозного радикализма. А культивирование патриотизма в системе общечеловеческих гуманных ценностей, развитие на его основе норм международного права и международной ответственности является важнейшим условием прогресса не только отдельного государства или государств, но и всего глобального социума в целом [11, с. 158-169].

Сегодня для российского общества патриотизм представляется тем фундаментом, на котором выстраивается его будущее: «Мы должны строить свое будущее на прочном фундаменте, - утверждает В.В. Путин, - и такой фундамент - это патриотизм. Мы, как бы долго ни обсуждали, что может быть фундаментом, прочным моральным основанием для нашей страны, ничего другого все равно не придумаем. Это уважение к своей истории и традициям, духовным ценностям наших народов, нашей тысячелетней культуре и уникальному опыту сосуществования сотен народов и языков на территории России. Нам необходимо в полной мере использовать лучший опыт воспитания и просвещения, который был и в Российской империи, и в Советском Союзе» [16].

Патриотизм как объединяющее звено консолидации общества выбрал коллективный разум народа, и именно эта идея не позволит в очередной раз разрушить наше государство. Сейчас стране нужна единая, объединяющая всех граждан идея, заявил в недавнем выступлении Владимир Владимирович Путин. И она уже есть, подчеркнул он. «У нас нет никакой и не может быть другой объединяющей идеи, кроме патриотизма. Никакой другой идеи мы не придумаем, и придумывать не надо», - передает слова Президента TACC. По мнению Президента, для внедрения национальной идеи недостаточно, чтобы Президент или еще кто-либо об этом сказал, пусть даже и сто раз. «Нужно, чтобы это вошло в сознание. Для этого нужно сознание, и постоянно об этом нужно говорить, на всех уровнях, постоянно», - уверен В.В. Путин [17].

«Высказывание В.В. Путина о патриотизме как объединяющей идее вполне логично», - заявил газете «Взгляд» политолог, член Общественной палаты, президент Фонда исследования проблем демократии Максим Григорьев. Он напомнил, что для каждой страны, которая осознает себя страной, чем, безусловно, является и Россия, патриотизм - одна из самых главных идей. О том, какая идея должна быть объединяющей, говорили многие, напомнил в беседе с газетой «Взгляд» политолог [18]. «Патриотизм четко сформулированная национальная идея от Путина. Я согласен с тем, что основной идеей должна быть любовь к Родине, то есть патриотизм», - считает политолог, исполнительный директор ассоциации НКО по защите избирательных прав «Гражданский контроль», директор Центра социально-политических исследований «Аспект» Георгий Федоров. «Владимир Путин сказал, что у нас есть национальная идея, и это патриотизм. Это констатация факта. Есть то, чем мы живем, и чем живет он, один из 145 миллионов граждан», - заявил газете «Взгляд» политолог Алексей Мартынов. Он напомнил, что лет 15-20 назад в экспертной среде и в СМИ было очень популярно говорить о том, что России нужна национальная идея и ее, дескать, нужно придумать, сформулировать - и тогда все будет хорошо. «Но народ, его коллективный 
разум всегда мудрее любого самого умного мыслителя. Общество сформулировало ее, и теперь для нас, современных граждан России, национальной идеей является патриотизм в хорошем смысле этого слова», - подчеркнул А. Мартынов. Он добавил, что патриотизм в здоровом смысле - «это очень большое, четкое и понятное слово, которое если даже не каждый сможет объяснить, то понимает каждый» [18].

Приоритетной, относящейся к стратегическим задачам, стоящим перед государством, является задача воспитания здорового, подрастающего поколения, со стабильными смысловыми устоями. Именно молодое поколение выступает гарантом благополучного развития страны и общества, поэтому представляет собой объект национально-государственных интересов.

Ввиду этого особую актуальность приобретает разработка стратегии, включающей как теоретическое обоснование, так и практические механизмы внедрения в воспитательный процесс мировоззренческих, нравственных и духовных основ сознательного служения Отечеству. Основой данной стратегии может быть многоплановое патриотическое воспитание молодого поколения, систематически и скоординированно выстроенное взаимодействие государственных институтов, общественных объединений и организаций, средств массовой информации по формированию у молодых людей патриотического сознания, любви к своему Отечеству [19, с. 6-13].

В сегодняшних реалиях особого внимания требует целенаправленная работа по формированию патриотических чувств у подрастающего поколения, целью которой является обеспечение исторической преемственности поколений, сохранение целостности общества, традиций, культуры и, самое главное, сохранение генофонда и государства.

Педагогический механизм патриотического воспитания молодежи, по утверждению Ж.Т. Тощенко, является совокупностью методов, форм и средств, обеспечивающих формирование, развитие, функционирование и сохранение патриотической идентичности в виде целостного морально-этического мировоззренческого комплекса и материализуется в конкретных институтах и технологиях [6, с. 137-142].

Функции таких технологий заключаются в распространении в обществе определенной идеологии путем внедрения национальных идеалов, ценностных ориентиров, образцов поведения; воспроизводство социально необходимых общественных отношений и институтов, формирующих патриотическое сознание граждан [20, с. 159].

Политика по отношению к молодежи формируется на уровне общества и государства. Государство обладает наибольшими ресурсами для проведения целостной молодежной политики. Главное действующее лицо будущего - это молодежь, а задача государства помочь молодым людям стать полноправными членами гражданского общества и устранить преграды на пути развития личности каждого молодого человека. «Мы сегодня поговорим о проблеме, которая давно назрела и часто на слуху, но вот так системно, пожалуй, не помню, чтобы она обсуждалась, - вопрос о патриотическом воспитании молодежи. На самом деле это разговор о самом главном: о ценностях, о нравственных основах, на которых мы можем и должны строить нашу жизнь, воспитывать детей, развивать общество, в конечном итоге укреплять нашу страну», - отметил В.В. Путин [10].
Изложенные в данной статье материалы дают возможность сделать вывод, что только систематическая, многогранная и скоординированная работа государственных и общественных организаций позволит вывести патриотизм в ранг ведущей идеи воспитания российской молодежи в современном социуме, реализация которой, прежде всего в системе образования, создаст условия для формирования патриотического сознания и нравственных ориентиров у молодежи.

\section{СПИСОК ЛИТЕРАТУРЫ:}

1. Гревцева Г.Я. Концепция гражданского воспитания: методологические аспекты // Гражданское образование: российский и зарубежный опыт: коллективная монография. Челябинск: Изд-во Челябинский государственный институт культуры, 2016. С. 288-301.

2. Даль В.И. Толковый словарь живого великорусского языка: в 4 т. М.: Рипол Классик, 2007. 3104 с.

3. Ожегов С.И. Толковый словарь русского языка / под ред. Л.Н. Скворцова. М.: Оникс-ЛИТ, Мир и Образование, 2012. $1376 \mathrm{c.}$

4. Кокорина Е.В. Трансформация лексической семантики и сочетаемости // Русский язык конца XX столетия (1985-1995). М.: Языки русской культуры, $2000.89 \mathrm{c}$.

5. Дубровин В.Л. Патриотизм как ресурс социального самоопределения в российском обществе. Ростов-на-Дону: Фонд науки и образования, 2015. 119 с.

6. Тощенко Ж.Т. Социология управления. М.: ЮРАЙТ, 2015. 303 c.

7. Дробижева Л.М. Государственная и гражданская идентичность в общероссийском пространстве // Гражданская, этническая и региональная идентичность: вчера, сегодня, завтра. М.: Российская политическая энциклопедия, 2013. С. 39-50.

8. Подвинцев О.Б. Представления о макрорегиональной структуре современной России как элемент и характеристика идентификационных схем // Человек в меняющемся мире. Проблемы идентичности и социальной адаптации в истории и современности: методология, методика и практики исследования: программа и тезисы. Томск: Издательство Томского университета, 2014. С. 180-181.

9. Патриотическое воспитание граждан Российской Федерации на 2016-2020 годы: государственная программа. Постановление Правительство Российской Федерации от 30 декабря 2015 г. № 1493, Москва.

10. Встреча с представителями общественности по вопросам патриотического воспитания молодежи [Электронный ресурс] // Информационный портал Президент России. - http://kremlin.ru/events/president/ news/16470.

11. Луков В.А. Молодежь в ситуации выбора // Человек перед выбором в современном мире: проблемы, возможности, решения: материалы Всероссийской научной конференции 27-28 октября 2015 г., ИФ РАН (Москва): в 3 т. Т. 2 / под общ. ред. М.С. Киселевой. М.: Научная мысль, 2015. С. 158-172.

12. Габидуллин И.Ф. Проблема формирования гражданско-правового сознания личности в современном мире: монография. М.: Дрофа, 2013. 276 с.

13. Циулина M.В. Патриотическое воспитание школьников возможностями социообразовательной среды: монография. Челябинск: Изд-во «Цицеро», 2012. 203 c. 
14. Циулина М.В. Методология психолого-педагогических исследований: учебное пособие. Челябинск: Челябинский государственный педагогический университет, 2015. 239 с.

15. Быков А.К. Современные научные проблемы патриотического воспитания молодежи // Известия Волгоградского государственного педагогического университета. 2006. № 1. С. 102-106.

16. Путин рассказал об истинной роли патриотизма [Электронный ресурс] // Информационный портал Путин сегодня. - http://putin-today.ru/archives/20508.

17. Путин: патриотизм - это и есть национальная идея [Электронный ресурс] // Информационное агентство ТАСC. - http://tass.ru/politika/2636647.

\section{PATRIOTISM AS A KEY NOTE OF RUSSIAN YOUNG EDUCATION IN MODERN SOCIETY}

(C) 2016
18. Путин рассказал об истинной роли патриотизма: Патриотизм как объединяющее звено [Электронный ресурс] // Деловая газета «Взгляд». - http:/vz.ru/ politics/2016/2/4/792180.html.

19. Лутовинов В.И. Критерии проявления гражданственности и патриотизма в современном российском обществе // Проблема формирования гражданина России через инструментарий идентичности: сборник. М.: Сотис, 2014. С. 6-13.

20. Кусмарцев М.Б. Социальная эффективность патриотического воспитания в регионе: условия, факторы, критерии: монография. Волгоград: Изд-во ВолГМУ, 2014. 172 с

\title{
E.L. Krylova, director \\ branch «The Russian Television and Radio Broadcasting Company "Samara"» of The Russian Television and Radio Broadcasting Company, Samara (Russia)
}

\begin{abstract}
The article states that patriotism is considered to be a key note of Russian youth's education, and the complex approach in the process of patriotic thinking development is highlighted. The mechanism of patriotic education consists of methods and means of development, functioning and saving moral-ethic ideology of patriotic orientation. The article proves the significance of young education that is based on such principles as respect of historical background, love for country and for national culture, as it is youth who provides productive development of a strong country and healthy society. The connection, where the core is universal values, between prosperous future of a country and youth's patriotic thinking is established. It is proved that true patriotism can only be aroused, but not dictated because young generation overreacts informational pressure. In these conditions, the aim of the media is to create a high quality information product adapted to the young audience. In this regard, media activity is considered as a complex of purposeful activities based on a combination of special knowledge, skills and values which develop the senses of love and loyalty to their country, readiness to defend their people, country and its interests.

Keywords: patriotism; young generation; idea; social life; patriotic thinking; media; historical memory; historical background propaganda; government program; information product; patriotism raising; social ideology.
\end{abstract}

УДК 378.147

\section{ПРОФЕССИОНАЛЬНО-ОРИЕНТИРОВАННОЕ ОБУЧЕНИЕ ИНОСТРАННОМУ ЯЗЫКУ КАК ОПЕРЕЖАЮЩИЙ ФАКТОР ПОДГОТОВКИ БУДУЩИХ НЕФТЯНИКОВ ДЛЯ РАБОТЫ НА ИННОВАЦИОННЫХ ПРЕДПРИЯТИЯХ}

(C) 2016

\author{
О.А. Ларионова, преподаватель английского языка
}

Альметьевский политехнический техникум, Альметьевск (Россия)

\footnotetext{
Аннотация. В статье рассмотрена проблема поиска способа повышения качества иноязычной подготовки студентов - будущих специалистов нефтегазовой отрасли. На основе анализа динамики внедрения инноваций как средства повышения конкурентоспособности в рамках мировой промышленности была выявлена потребность в овладении профессионально-ориентированным языком специалистами нефтегазовой отрасли. Автор рассматривает данный уровень владения иностранным языком как многофункциональный инструмент, непосредственно влияющий на специалиста, на промышленный процесс и на требования работодателя к специалисту. Автором ставится задача устранения рекламации социального заказа на специалистов для нефтяных инновационных предприятий и повышения уровня иноязычной подготовки выпускников техникума (колледжа, вуза). В качестве решения сложившихся противоречий предлагается внедрение курса «Интегративный английский язык» для будущих нефтяников. Особое внимание обращается на построение этого курса. Автор предлагает строить курс на основе ряда выделенных и описанных принципов. Отмечается, что обучение профессионально-ориентированному иностранному языку с применением интегративного подхода и отобранного по выделенным принципам содержания позволит сформировать тот уровень английского языка, который будет удовлетворять личные потребности специалиста, потребности предприятия и позволит вывести организацию на конкурентоспособный уровень на мировом рынке труда.

Ключевые слова: конкурентоспособность; инновации; социальный заказ на специалиста; знание технического английского языка; интегративный подход; многофункциональный инструмент; принципы построения курса «Интегративный английский язык».
} 